\title{
Gravid uterus in a neglected incisional hernia: a rare case report
}

\author{
Rohini R. Raut*, Rangan Bhattacharya, Snehal G. Murde
}

Department of Obstetrics and Gynaecology, Dr Babasaheb Ambedkar Memorial Hospital, Byculla, Mumbai, Maharashtra, India

Received: 07 September 2020

Accepted: 08 October 2020

\section{*Correspondence:}

Dr. Rohit R. Raut,

E-mail: dr.rohu19@gmail.com

Copyright: (C) the author(s), publisher and licensee Medip Academy. This is an open-access article distributed under the terms of the Creative Commons Attribution Non-Commercial License, which permits unrestricted non-commercial use, distribution, and reproduction in any medium, provided the original work is properly cited.

\begin{abstract}
Incidence of incisional hernia in pregnancy is rare and is mainly managed conservatively. An ideal technique for repairing incisional hernia in pregnant patients has yet to be established, but it is clear that each case must be dealt with on an individual basis. It is essential for surgeons to consider the length of the surgery, the presence of contamination, the age of the fetus, the size of the defect, and the chances of recurrence before selecting which technique to employ when repairing abdominal wall hernia in pregnancy. We report a case of term pregnancy in a third gravida, aged 30 years with previous two vaginal deliveries with incisional hernia with overlying hyperpigmented lax skin patch. Incisional hernia developed as a complication because of the previous surgical history of open appendectomy 10 years back which was complicated in the post-operative period, 22 days later leading to an emergency laparotomy in view of intestinal obstruction. Caesarean section was done with simultaneous repair of the incisional hernia with nonabsorbable sutures. The post-operative recovery was uneventful.
\end{abstract}

Keywords: Incisional hernia, Pregnancy, Emergency laparotomy

\section{INTRODUCTION}

Incisional hernias appear at a rate of $18.7 \%$ in a study of 10 -year follow-up post-surgery. ${ }^{1}$ However, the incidence of these hernias during pregnancy is unknown as only case reports exist in the literature. ${ }^{1}$ In a pregnant patient, the clinical presentation of a hernia is not always clear cut. One may confuse the often variable and vague symptoms with morning sickness or uterine contractions. ${ }^{2,3}$ It is critical that physicians thoroughly examine this patient population for the possibility of a hernia to avoid potentially adverse and even morbid outcomes for the mother and fetus. Post-operative abdominal distension, intra-abdominal sepsis, residual intra-abdominal abscess, wound infection, wound dehiscence and post-operative fever contribute significantly to the incidence of incisional hernia. ${ }^{4}$ Managing these hernias depends on the emergent nature of the situation and the gestational age at the time of presentation. ${ }^{1}$ While hernias are often asymptomatic and can be treated conservatively during pregnancy, some may become incarcerated, strangulated, or irreducible requiring immediate surgical intervention..$^{1,6}$ The mortality rate is high for both the mother and the fetus in the case of a strangulated hernia., ${ }^{7,8}$

\section{CASE REPORT}

We report a case of a 30 years old female, gravid 3, para 2 , living 2 referred from a peripheral hospital, at 38 weeks gestation with incisional hernia in labour. Patient presented with the complaint of pain in abdomen. On detailed history taking, it was found that, she had previous two vaginal deliveries. Incisional hernia developed as a complication because of the previous surgical history of emergency open appendectomy 10 years back through right paramedian incision; which was complicated in the post-operative period, 22 days later, leading to an emergency laparotomy again in view of intestinal obstruction. The hernia developed after this surgery, but the patient neglected it. It gradually enlarged during the present pregnancy. She had no complaint of nausea, vomiting or fever. On examination, she was vitally stable. 
Per abdomen examination revealed, uterus corresponding to 36 weeks gestation, palpable directly under the skin. Uterus was having regular contractions. On palpation, a fetus in cephalic presentation with engaged head was found. Fetal heart sound was good. A right lower paramedian scar, surrounded by redundant hyperpigmented lax skin patch of $13 \times 14 \mathrm{~cm}$ with incisional hernia was seen.

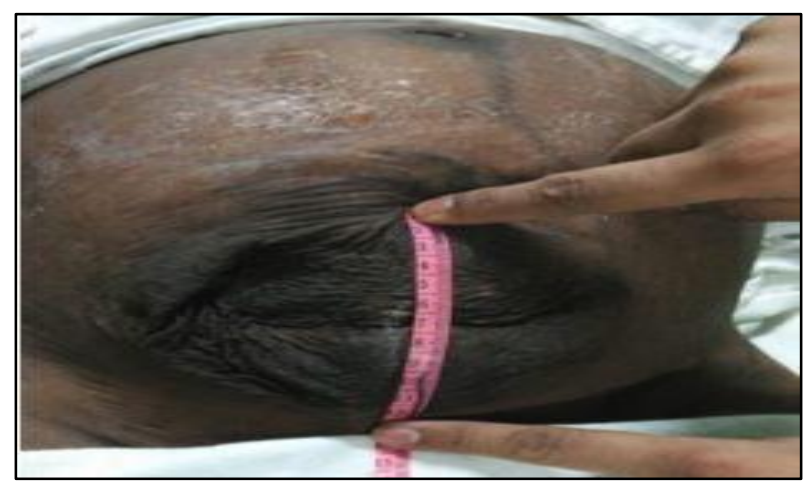

Figure 1: Hyperpigmented redundant skin patch surrounding incisional hernia.

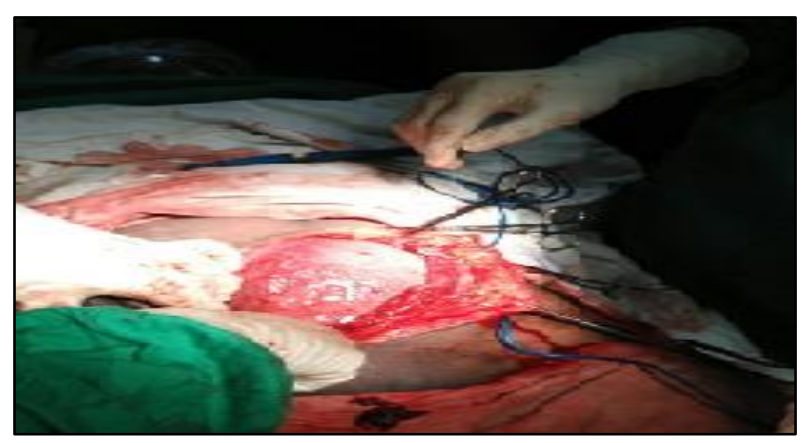

Figure 2: Uterus directly revealed on opening the abdomen.

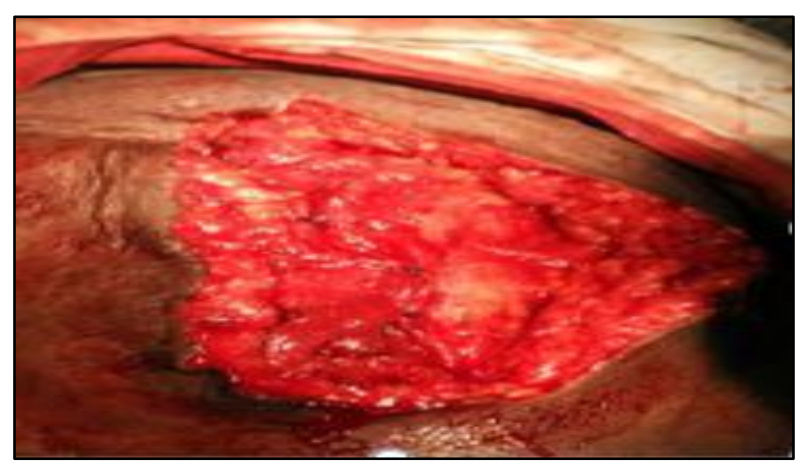

Figure 3: Rectus muscle and sheath apposed.

All her routine blood investigations were within normal limits. She was taken up for a caesarean section with simultaneous hernia repair. Vertical midline incision taken bypassing the redundant skin. On opening the abdomen, rectus sheath and muscle were completely thinned out, directly revealing the uterus.
Bladder was pushed down. Lower segment transverse uterine incision taken, and $2.5 \mathrm{~kg}$ female baby was delivered. Uterus was closed. Hemostasis checked. A team of surgeons was called for hernia repair. Intra-operatively, multiple interbowel adhesions were found. However, on examination bowel appeared normal. Appendix not visualized. Rectus muscle and sheath thinned out. Adequate mobilization of rectus muscle and sheath from the overlying subcutaneous tissue was done and was approximated with non-absorbable sutures. Hernioraphy completed.

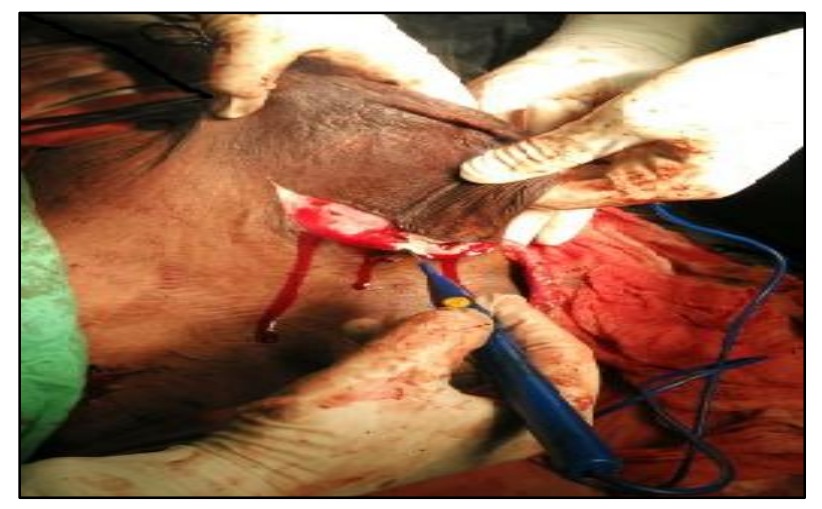

Figure 4: Redundant skin being excised.

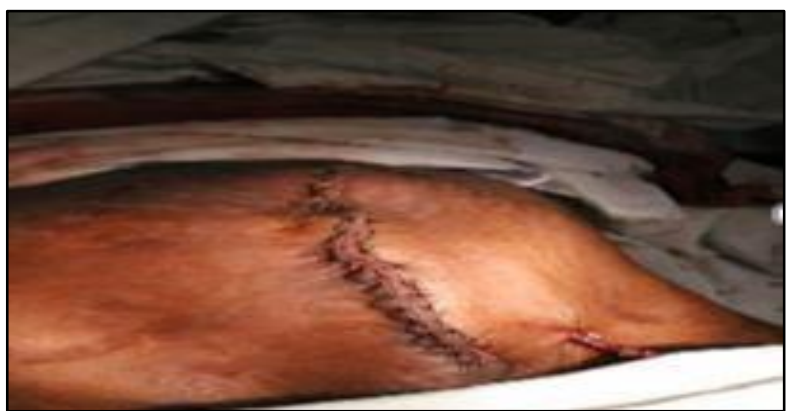

Figure 5: Skin closure.

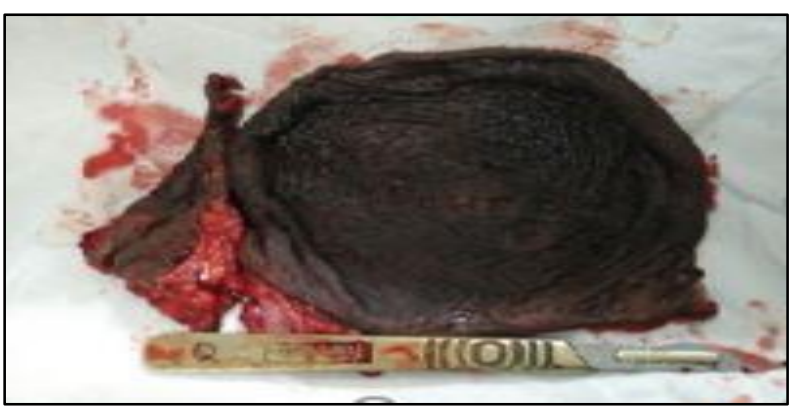

Figure 6: Excised redundant skin.

The redundant skin on right side was excised and the wound was closed with a suction drain after checking hemostasis.

Skin closed with vertical mattress sutures using nonabsorbable sutures. 


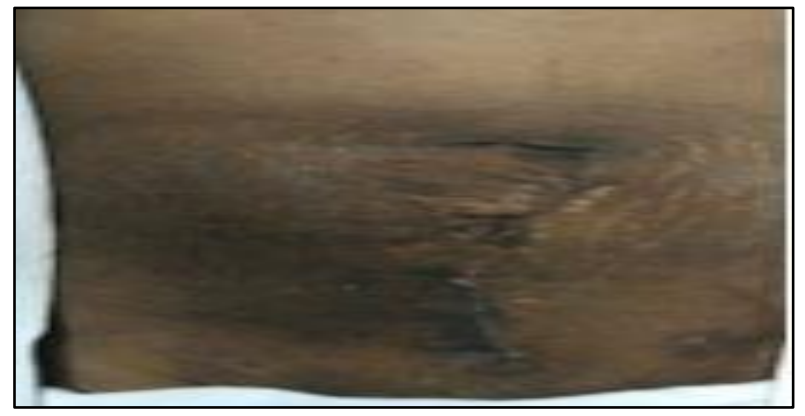

Figure 7: Healed wound with healthy scar.

Recovery was uneventful and the patient was discharged after removing the stitches on the tenth postoperative day. At six weeks follow up visit, she had no complaints and her scar was well healed.

\section{DISCUSSION}

The ideal management of incisional hernia in pregnancy is unknown. Both open and laparoscopic hernia repair are possible in pregnancy. An open technique may be a more familiar and quicker approach while laparoscopic hernia repair may be more difficult in the presence of strangulated hernia. ${ }^{5}$ Since the Luijendijk et al study in 1990, the gold standard for incisional hernia repair in the general population is permanent, synthetic mesh reinforcement. ${ }^{2}$ However, implanting synthetic mesh is relatively contraindicated in the setting of a contaminated surgical field. Primary suture repair is a safe option in pregnancy when the fascial defect can be closed without significant tension, although the recurrence rate is likely higher. ${ }^{2}$ Hernia repair with an absorbable, synthetic mesh can also be used, particularly when a large defect is present, but again, recurrent hernia would be likely. Another consideration is to use a bio prosthetic mesh. These devices have been successfully used in contaminated and infected hernia operations. ${ }^{3}$ However, the risk to the fetus when using a biologic implant for hernia repair is unknown. In addition, the cost of bio prosthetic mesh is high, and the effect of the increased biomechanical stress and strain of the gravid uterus on the abdominal wall-bio prosthetic interface is unpredictable.

The development of an infected hernia mesh is a devastating event for the patient. Risk factors include the following: patient age, American Society of Anesthesiologists score, tobacco use, and the duration and emergency setting of the operation. ${ }^{9}$ One must consider each case individually and account for the length of the operation, the presence of contamination, the gestational age, the size of the defect, and the likelihood of recurrence when deciding on the technique to repair abdominal wall hernias in pregnancy. ${ }^{5}$

Long-term complications and impact on future pregnancies necessitate carefully planned management of these patients. The possible complications include preterm labour, abortion, strangulation, haemorrhage, intrauterine growth restriction, intrauterine fetal death, dysfunctional labour, rupture of the lower uterine segment, and postpartum haemorrhage amongst others. ${ }^{11}$ The therapeutic options include a caesarean section which offers a means of hernia repair during surgery, as opposed to vaginal birth which involves delayed repair. ${ }^{10}$ However, given the uncertainties about the integrity of the anterior abdominal wall during labour especially in the case of an incisional hernia, elective caesarean section is considered by many obstetricians as the safest mode of delivery. ${ }^{10}$ During these caesarean sections, concomitant hernioraphy can be carried out. ${ }^{11}$ Reports of subsequent pregnancies after hernioraphy following herniation of a gravid uterus are uncommon in the literature.

\section{CONCLUSION}

Pregnancy with incisional hernia is a rare occurrence. Management is mainly conservative. Simultaneous hernia repair with caesarean section is safe and generally preferred. During emergency operations including cesarean sections, surgical principles should always be observed in order to prevent the occurrence of incisional hernia.

\section{ACKNOWLEDGMENTS}

We acknowledge the help of our entire team of obstetricians, surgeon, anesthetist, operation theatre staff for their help and cooperation. The woman and her whose story is told in this case report, cooperated in our work signed permission for its publication.

Funding: No funding sources Conflict of interest: None declared Ethical approval: Not required

\section{REFERENCES}

1. Young BC, Fugelso D, Takoudes T. Incisional hernia with bowel incarceration and obstruction at 34 weeks gestational age. Arch Gynecol Obstet. 2009;279(6):905-7.

2. Luijendijk RW, Hop WC, van den Tol MP, de Lange DC, Braaksma MM, JN IJ, et al. A comparison of suture repair with mesh repair for incisional hernia. $\mathrm{N}$ Engl J Med. 2000;343(6):392-8.

3. Franklin ME Jr., Trevino JM, Portillo G, Vela I, Glass JL, Gonzalez JJ. The use of porcine small intestinal submucosa as a prosthetic material for laparoscopic hernia repair in infected and potentially contaminated fields: long-term follow-up. Surg Endosc. 2008;22(9):1941-6.

4. Adesunkanmi AR, Faleyimu B. Incidence and etiological factors of incisional hernia in postcaesarean operations in a Nigerian hospital. J Obstet Gynaecol. 2003;23:258-60.

5. Dorion H, Hileman B. Abdominal Wall Reconstruction Following Strangulated Recurrent 
Incisional Hernia During Pregnancy. J Med Cases. 2013;4(12):796-8.

6. Torres-Villalobos GM, Kellogg TA, Leslie DB, Antanavicius G, Andrade RS, Slusarek B, et al. Small bowel obstruction and internal hernias during pregnancy after gastric bypass surgery. Obes Surg. 2009; 19(7):944-50.

7. Moore KA, Ouyang DW, Whang EE. Maternal and fetal deaths after gastric bypass surgery for morbid obesity. N Engl J Med. 2004;351(7):721-2.

8. Wai PY, Ruby JA, Davis KA, Roberts AC, Roberts KE. Laparoscopic ventral hernia repair during pregnancy. Hernia. 2009;13(5):559-63.

9. Mavros MN, Athanasiou S, Alexiou VG, Mitsikostas PK, Peppas G, Falagas ME. Risk factors for meshrelated infections after hernia repair surgery: a metaanalysis of cohort studies. World J Surg. 2011;35(11):2389-98.
10. Rao RS, Shankaregowda HS. A case of herniated gravid uterus through a laparotomy scar. Ind J Med Sci. 2006;60(4):154-7.

11. Chaudhuri S, Mitra SN, Daga A, Bandopadhyay D. Gravid uterus in an anterior abdominal wall hernia and successful repair at the time of caesarean section. Brit J Med Pract. 2009;2(4)57-8.1:713-21.

Cite this article as: Raut RR, Bhattacharya $\mathrm{R}$, Murde SG. Gravid uterus in a neglected incisional hernia: a rare case report. Int J Reprod Contracept Obstet Gynecol 2020;9:4769-72. 